\section{Serum Inhibin B als ein Marker der Spermatogenese}

Zusammenfassung. Inhibin B wird von Sertolizellen produziert und reguliert die FSH-Sekretion über einen negativen Feedback. Beim Mann scheint Inhibin B die physiologisch bedeutsame Form zu sein. Wir bestimmten Serum-Inhibin B unter Verwendung eines zwei-Seiten-immunoenzymatischen Assays bei 40 Normalpersonen (Alter: 27,37 $\pm 0,83$ Jahre, Mittelwert \pm Standardfehler) mit einer Spermienkonzentration von $100,0 \pm 9,2 \times 10^{6} / \mathrm{ml}$, bei 51 subfertilen Patienten $(30,86 \pm 0,94$ Jahre) mit einer Spermienkonzentration von $6,8 \pm 0,8 \times 10^{6} / \mathrm{ml}$, bei Männern mit Varikozele $(n=16)$ mit einer Spermienkonzentration von $54,3 \pm 17,1 \times 10^{6} / \mathrm{ml}$ und einem Alter von 30,69 $\pm 1,52$ Jahren, sowie von Männern mit Kallmann-Syndrom, KlinefelterSyndrom, obstruktiver und nicht obstruktiver Azoospermie. Wir verglichen Serum-Inhibin-B-Konzentrationen mit Serum FSHund Spermienkonzentration. Bei Männern mit normaler Spermienkonzentration (>20 $\times 10^{6} / \mathrm{ml}$ ) betrugen die Konzentrationen von Inhibin B im Serum 201,5 $\pm 17,1 \mathrm{pg} / \mathrm{ml}$ und von FSH $4,1 \pm 0,5 \mathrm{IU} / \mathrm{l}$. Die Patienten mit Varikozele zeigen ebenfalls eine Spermienkonzentration $>20 \times 10^{6} / \mathrm{ml}$ und liegen mit ihren Serum-Inhibin-B-Werten im Bereich von $173,7 \pm 21,3 \mathrm{pg} / \mathrm{ml}$; die FSH-Werte liegen bei 4,6 $\pm 0,6 \mathrm{IU} / \mathrm{l}$. Bei Patienten mit Spermienkonzentrationen $<20 \times 10^{6} / \mathrm{ml}$ betrug die Inhibin-B-Konzentration $118,2 \pm 14,8 \mathrm{pg} / \mathrm{ml}$ und die FSH-Konzentration lag bei $10,1 \pm 1,1 \mathrm{IU} / \mathrm{l}$. Bei allen Patienten, außer jenen mit hypogonadotropem Hypogonadismus und Klinefelter-Syndrom, war die Korrelation zwischen Inhibin B und FSH invers $(r=-0,41, P>0,01)$. Die Spermienzahl korrelierte positiv mit den Serum-Inhibin-BKonzentrationen $(r=0,340, P<0,01)$. Eine Korrelation von $r=0,574, P<0,05$ ergab sich bei der Gruppe mit Varikozele. Aus den Untersuchungen lässt sich schlussfolgern, dass Inhibin B ein Marker der exokrinen testikulären Funktion ist und eine sehr wesentliche Hilfe zur Diagnosestellung testikulärer Funktionsstörungen darstellt.

Inhibin B as Marker of Spermatogenesis. Inhibin B generated by Sertoli cells provides negative feedback on FSH secretion. In men, inhibin B seems to be the physiologically important form of inhibin. Therefore we measured serum inhibin $B$ using a new two-site immunoenzymatic assay in $\mathbf{4 0}$ healthy men (age $27.37 \pm 0.83$ years (mean $\pm S E M$ ) with sperm concentrations

Akt Dermatol 2001; 27: 273-278

(c) Georg Thieme Verlag Stuttgart · New York ISSN 0340-2541
Uta-Christina Hipler, B. Hochheim, B. Knöll, J. Tittelbach, G. Schreiber

Klinik für Hautkrankheiten der Friedrich-Schiller-Universität Jena (Direktor: Prof. Dr. P. Elsner)

$100.0 \pm 9.2 \times 10^{6} / \mathrm{ml}$, in 51 subfertile men $(30.86 \pm 0.94$ years) with sperm concentrations $6.8 \pm 0.8 \times 10^{6} / \mathrm{ml}$, in men with varicocele $(n=16)$ with sperm concentrations $54.3 \pm 0.8 \times 10^{6} / \mathrm{ml}$ $(30.6 \pm 1.5$ years) and in men with hypogonadotrophic hypogonadism, Klinefelter syndrome, in men with obstructive and non-obstructive azoospermia. We compared serum inhibin B concentrations with serum FSH and sperm concentrations. In men with normal sperm concentrations $\left(>20 \times 10^{6} / \mathrm{ml}\right)$ we measured serum inhibin B concentrations $201.5 \pm 17.1 \mathrm{pg} / \mathrm{ml}$ and the FSH concentrations $4.1 \pm 0.5 \mathrm{IU} / \mathrm{L}$. The varicocele patients showed normal sperm concentrations $>20 \times 10^{6} / \mathrm{ml}$ and the serum inhibin $B(173.7 \pm 21.3 \mathrm{pg} / \mathrm{ml})$ and the $\mathrm{FSH}$ values $(4.6 \pm 0.6 \mathrm{IU} / \mathrm{L})$ we obtained were in the same range, respectively. In patients with sperm concentrations $<20 \times 10^{6} / \mathrm{ml}$ the concentration of inhibin B was $118.2 \pm 14.8 \mathrm{pg} / \mathrm{ml}$ and the FSH concentration was $10.1 \pm 1.1 \mathrm{IU} / \mathrm{L}$. In all patients, except those with hypogonadotrophic hypogonadism and Klinefelter syndrome, the inhibin B and FSH correlated inversely $(r=-0.41, P>0.01)$. $A$ positive correlation between inhibin $B$ and sperm concentrations could be shown $(r=0.34, P<0.01)$. In the varicocele group a correlation of $r=0.574, P<0.05$ was found. We conclude that inhibin $B$ may be regarded as a marker of exocrine testicular function and could offer an improved diagnosis of testicular disorders.

\section{Einleitung}

Andrologie ist ein interdisziplinäres Gebiet, das sich mit der (Patho-)Physiologie der männlichen Fertilität beschäftigt. Der klinische Schwerpunkt liegt in der Diagnostik und Therapie männlicher Fertilitätsstörungen. Die Untersuchung männlicher Fertilitätsstörungen erfasst primäre oder sekundäre Hodenschäden als mögliche Ursache.

Neben Anamnese und klinischer Untersuchung ist die Labordiagnostik von großer Bedeutung. Das Laborprogramm umfasst das Spermiogramm mit mikroskopischer Untersuchung sowie die biochemische Analyse des Seminalplasmas mit der Bestimmung von Zitronensäure, Fructose, Elastase und $\alpha$-Glucosidase. Hormonbestimmung, Hodenbiopsie, Chromosomenuntersuchung. Immunologische Testungen und Spermienfunktionstests (Penetrak, HOS-Test) schließen eine umfassende Diagnostik ab. 
Viele Zusammenhänge auf dem Gebiet der männlichen Fertilitätsstörungen sind noch nicht genügend aufgeklärt. So sucht man nach neuen diagnostischen Methoden zur gezielten Aufklärung von Schäden in testikulären Kompartimenten. Neben dem grundsätzlichen Verständnis dieser Prozesse erhofft man sich davon natürlich auch das Auffinden neuer Therapieansätze.

Von zunehmendem Interesse ist die Superfamilie des TGF $\beta$ (transforming growth factor), eine Proteinfamilie, zu der auch das Inhibin gehört. Schon 1923 [18] wurde erstmals der Begriff Inhibin geprägt. Bei der Bestrahlung von Rattentestes wurde beobachtet, dass es zur Hypertrophie von spezifischen Zellen und dabei zum Freisetzen einer Substanz kommt, der man den Namen Inhibin gab. Im Jahre 1932 wurde von McCullagh [16] die Existenz eines wasserlöslichen Hormons, produziert durch die Testes, mit einer Feedback-Wirkung auf die Hypophyse vorgeschlagen.

50 Jahre beschäftigte sich jedoch niemand mit der Forschung zum Inhibin. Erst im Jahre 1985 wurde Inhibin aufgereinigt und isoliert. Vier verschiedene Arbeitsgruppen isolierten Inhibin aus Schweine- und Rinderfollikelflüssigkeit [9].

Es existieren verschiedene zirkulierende Inhibinformen, von denen jedoch einige als biologisch inaktiv angesehen werden [20]. In seiner biologisch aktiven Form ist Inhibin ein dimeres Protein, bestehend aus einer $\alpha$-Subeinheit, gebunden entweder an eine $\beta_{A}$-Subeinheit (Inhibin A) oder an eine $\beta_{B}$-Subeinheit, (Inhibin B) [6]. Die $\alpha$-Subeinheit ist nur in einer Form, einem 18-KDa-Polypeptid bekannt, während von der $\beta$-Subeinheit zwei ähnliche Formen, $\beta_{\mathrm{A}}$ und $\beta_{\mathrm{B}}$, aber mit unterschiedlichen Peptiden von 14 KDa Molekulargewicht, existieren. Die Bindung in den Inhibin-Dimeren erfolgt über Disulfidbrücken.

Es wird angenommen, dass Inhibin B die FSH-Sekretion durch einen negativen Feedback-Mechanismus reguliert. Dies konnte sowohl durch In-vitro-Studien [12] als auch durch In-vivoExperimente an Tieren gezeigt werden [4].

Es war jedoch bis vor kurzem nicht möglich, bei Männern eine negative Beziehung zwischen dem zirkulierenden immunreaktiven Inhibin und dem FSH zu zeigen [10].

Frühere Immunoassays für Inhibin besaßen eine $\mathrm{zu}$ große Kreuzreaktivität mit inaktiven monomeren und dimeren Percursoren, die im Plasma anwesend sind. Dies hatte einen Verlust an Selektivität und Schwierigkeiten bei der Unterscheidung zwischen Inhibin A und Inhibin B zur Folge [19]. Frühere Inhibinassays, wie zum Beispiel der Monash-Radioimmunoassay, konnten nicht zwischen den bioaktiven Formen und freien $\alpha$-Subeinheiten unterscheiden.

Erst die Entwicklung einer neuen Generation von Immunoassays durch Groome et al. [7] und die Herstellung der entsprechenden monoklonalen Antikörper gegen Inhibin und seine Subeinheiten ermöglichte die Messung des Inhibin B bei Männern. Dieser neue, für Inhibin B spezifische ELISA zeigte, dass gerade dieses Inhibin die zirkulierende bioaktive Form bei Männern ist. Zirkulierendes Inhibin A konnte bei Männern nicht nachgewiesen werden [10].
Darüber hinaus ist gefunden worden, dass die Inhibin-B-Werte bei jenen Männern nicht nachweisbar sind, die eine durch Störungen der Spermatogenese hervorgerufene Azoospermie (idiopathische Azoospermie) besitzen [2]. Anhand der Inhibin-B-Werte kann man zwischen einer obstruktiven und idiopathischen Azoospermie unterscheiden.

Klingmüller et al. [14] zeigten ebenfalls in ihren Untersuchungen, dass Azoospermie-Patienten und Patienten mit Klinefelter Syndrom keine nachweisbaren Inhibin-B-Konzentrationen aufweisen. Damit konnte auch bestätigt werden, dass Inhibin $B$ in den Sertolizellen der Hodentubuli produziert wird.

Es existieren zahlreiche Arbeiten, die sich mit der Beeinflussung des Inhibin-B-Spiegels durch verschiedene Substanzen wie FSH oder Dibutyryl-cAMP beschäftigen, da daraus Rückschlüsse auf die Sertolizellfunktion gezogen werden können [21].

Für die Zukunft ist denkbar, dass Sertolizellkulturen von Ratten eine Möglichkeit bieten, Substanzen auf ihre Zytotoxizität zu testen und mit der Messung der Inhibin-B-Konzentrationen einen Marker für die schädigende Wirkung dieser Substanzen auf die Spermatogenese in der Hand zu haben [1]. Zusätzlich zum Inhibin B könnte man an eine Messung der reaktiven Sauerstoffspezies mit Hilfe von Fluoreszenzfarbstoffen (z. B. 2',7'Dichlorofluoreszein) denken.

\section{Material und Methoden}

\section{Patienten}

Es wurden 40 Normalpersonen mit einem normalen Spermiogramm nach WHO [22] mit einer Spermienkonzentration $>20 \times 10^{6} / \mathrm{ml}$ und einem Alter von 27,3 \pm 1 Jahren (Mittelwert \pm Standardfehler), 4 Patienten mit hypogonadotropem Hypogonadismus mit einem Alter von 23,2 \pm 1,2 Jahren, 5 Patienten mit einem Klinefelter-Syndrom mit einem Alter von 34,6 \pm 5,3 Jahren, 29 Patienten mit einer nicht obstruktiven Azoospermie mit einem Alter von 28,8 $\pm 1,1$ Jahren, 4 Patienten mit einer obstruktiven Azoospermie mit einem Alter von $32 \pm 2,4$ Jahren, 16 Patienten mit Varikozele und einem Alter von 30,7 $\pm 1,5$ Jahren und 51 subfertile Patienten (Spermienkonzentration $<20 \times 10^{6} / \mathrm{ml}$ ) und einer Altersverteilung von $30,8 \pm 0,9$ Jahren untersucht. Die Blutentnahme erfolgte zwischen 8 und 11 Uhr.

Das Blut wurde bei $4000 \mathrm{U}$ für 15 min zentrifugiert und bei $-20^{\circ} \mathrm{C}$ aufbewahrt, bis der Assay durchgeführt wurde.

\section{Hormonanalyse}

Das humane luteinisierende Hormon (LH) und das humane follikelstimmulierende Hormon (FSH) wurden mit den verfügbaren kommerziellen Enzymimmunoassays von Abbott bestimmt. Die Normalbereiche des AXSYM $^{\circledR}$ LH-Assays liegen bei 2-12 IU/l und für AXSYM ${ }^{\circledR}$ FSH bei $1-8 \mathrm{IU} / 1$. Die Nachweisgrenze von LH und FSH wird mit 0,2 IU/1 angegeben. Die Intraassay-Variationen für LH und FSH liegen zwischen 3\% und 6\% und die Interassay-Variationen zwischen $6 \%$ und $10 \%$. Für die quantitative Bestimmung von Gesamt-Testosteron (gebundenes und ungebundenes) im Serum wurde das Automatische Chemilumineszenz-System ACS: Centaur ${ }^{\mathrm{TM}}$ von Chiron Diag- 
nostics eingesetzt. Der Normalbereich für Testosteron wird bei Männern mit 8,4-28,7 nmol/l (241-827 ng/dl) festgelegt.

\section{Testikuläres Volumen}

Das testikuläre Volumen wurde mit Hilfe des Prader Orchidometers bestimmt.

\section{Spermiogramm}

Die Durchführung des Spermiogramms erfolgte entsprechend der WHO-Vorschrift [22].

\section{Statistische Auswertung}

Die statistische Auswertung wurde mit dem Programm SPSS 7.5 für Windows durchgeführt. Dabei wurde der Mann-Whitney-U-Test angewendet und ein P-Wert $<0,05$ als signifikant betrachtet.

\section{Testprinzip}

Der dimere Inhibin B-Immunoassay (Serotec, Vertrieb Biozol, Deutschland) ist ein Festphasensandwich-ELISA (Enzym-gebundener Immuno Sorbent Assay). Die Mikrotiterplatte ist mit einem monoklonalen Antikörper beschichtet, der gegen die $\beta_{B}$-Subeinheit von Inhibin gerichtet ist. Die Proben sowie die Standards und die entsprechenden Kontrollen werden direkt in der Mikrotiterplatte inkubiert, so dass das Antigen an den Capture-Antikörper über seine $\beta_{\mathrm{B}}$-Subeinheit gebunden wird. Es folgt eine Waschprozedur, bevor der Nachweisantikörper hinzugefügt wird. Dies ist ein mit alkalischer Phosphatase gekoppelter monoklonaler Antikörper, der spezifisch an die $\alpha$-Subeinheit von Inhibin bindet.

Ungebundenes Material wird durch das Waschen beseitigt, bevor der Nachweis der alkalischen Phosphatase unter Verwendung eines sensitiv verstärkenden Substrates durchgeführt wird. Als Ergebnis erhält man ein Reaktionsprodukt, dessen Farbintensität proportional zur Konzentration des dimeren Inhibin B in der Probe ist.

Bevor der ELISA durchgeführt wird, werden die Patientenproben und Standards mit dem Detergenz SDS vorbehandelt, auf $100^{\circ} \mathrm{C}$ erhitzt und mit $\mathrm{H}_{2} \mathrm{O}_{2} 30$ min bei Raumtemperatur inkubiert. Die Inkubation mit $\mathrm{H}_{2} \mathrm{O}_{2}$ modifiziert die $\beta_{\mathrm{B}}$-SubeinheitEpitope und erhöht deren Reaktivität mit dem entsprechenden
Antikörper. Diese Prozedur basiert auf den Arbeiten von Knight und Muuttukrishna [15].

Diese Behandlungen erhöhen die Spezifität und die Sensitivität des ELISA. Der Inhibin-B-Assay besitzt eine Nachweisgrenze von $5 \mathrm{pg} / \mathrm{ml}$. Die Variationskoeffizienten für den Intraassay und den Interassay liegen zwischen 5-7\% bzw. 6-10\%.

\section{Ergebnisse}

Bei Männern mit normalen Spermienkonzentrationen $\left(100,0 \pm 9,2 \times 10^{6} / \mathrm{ml}\right)$, dazu zählt auch die Gruppe mit Varikozele $\left(54,38 \pm 17,12 \times 10^{6} / \mathrm{ml}\right)$, waren die Serum-Inhibin-B-Konzentrationen signifikant höher $(P<0,01)$ als bei Patienten mit niedriger Spermienkonzentration $\left(6,8 \pm 0,80 \times 10^{6} / \mathrm{ml}\right)$. Sie betrugen für die erste Patientengruppe $201,5 \pm 17,1 \mathrm{pg} / \mathrm{ml}$, für die Gruppe mit Varikozele $173,7 \pm 21,3 \mathrm{pg} / \mathrm{ml}$ und für die Patienten mit niedrigen Spermienkonzentrationen $118,2 \pm 14,8 \mathrm{pg} / \mathrm{ml}$. Bei Patienten mit hypogonadotropem Hypogonadismus und Klinefelter Syndrom lagen die Inhibin-B-Werte bei $47,4 \pm 22,6$ pg/ml bzw. 13,6 $\pm 8,5$ pg/ml. Bei Berücksichtigung des Standardfehlers bedeutet dies für das Klinefelter-Syndrom, dass die Inhibin B-Werte nicht nachweisbar sind (s. Tab. 1).

Bei allen Patienten korrelierten die Spermienzahlen positiv mit der Serum Inhibin B-Konzentration $(r=0,438, P<0,01)$ und negativ mit der FSH-Konzentration $(r=-0,483, P<0,01)$. In Abb. 1 wird die Serum Inhibin-B- und FSH-Korrelation bei allen Patienten aufgezeigt $(r=-0,48, P<0,001)$ und in Abb. 2 die Korrelation bei der Patientengruppe mit nicht obstruktiver Azoospermie $(r=-0,41, P<0,05)$ gezeigt. In Abb. 3 wird die Inhibin $\mathrm{B}$ und FSH-Korrelation bei der subfertilen Gruppe $(\mathrm{r}=-$ $0,41, P<0,05)$ dargestellt. Die Abb. 4 zeigt eine positive Korrelation zwischen Serum-Inhibin B und Spermienzahl bei Patienten mit Varikozele $(r=0,574, \mathrm{P}<0,05)$. Die Serum-InhibinB-Werte korrelierten signifikant mit den Mittelwerten der Hodenvolumina $(r=0,96, P<0,0005)$.

\section{Diskussion}

Von Crofton et al. [5] wurde erstmals der von Groome et al. entwickelte Inhibin-B-Assay [8] bei Jungen in der Pubertät verwendet. Es zeigte sich, dass Konzentrationen innerhalb der pubertären Stadien 1 bis 3 (ANOVA < 0,0001) zunimmt und stark mit dem testikulären Volumen $(r=0,72, P=0,0005)$ korreliert. Präpubertäre Jungen wiesen eine positive Korrelation zwischen Inhibin B und FSH $(r=0,65, P=0,056)$ auf, während bei pubertären Jungen eine stark negative Korrelation $(r=-0,75$,

Tab.1 Klinische und biochemische Daten von Patienten mit normaler oder gestörter Spermatogenese

\begin{tabular}{lccccc}
\hline Patienten (n) & $\begin{array}{l}\text { Spermienkonzentration } \\
\left(\times 10^{6} / \mathrm{ml}\right)\end{array}$ & $\begin{array}{l}\text { FSH } \\
(\mathrm{IU} / \mathrm{l})\end{array}$ & $\begin{array}{l}\text { Inhibin B } \\
(\mathrm{pg} / \mathrm{ml})\end{array}$ & $\begin{array}{l}\text { Alter } \\
(\text { Jahre })\end{array}$ & $\begin{array}{l}\text { Hodenvolumen } \\
(\mathrm{ml})\end{array}$ \\
\hline Normalpersonen (40) & $100,0 \pm 9,2$ & $4,1 \pm 0,5$ & $201,5 \pm 17,1$ & $27,3 \pm 0,8$ & $19,0 \pm 0,8$ \\
Subfertile (51) & $6,8 \pm 0,8$ & $10,1 \pm 1,1$ & $118,2 \pm 14,8$ & $30,8 \pm 0,9$ & $11,0 \pm 1,1$ \\
Varikozele (16) & $54,3 \pm 17,1$ & $4,6 \pm 0,6$ & $173,7 \pm 21,3$ & $30,6 \pm 1,5$ & $19,0 \pm 1,9$ \\
Kallmann-Syndrom (4) & 0 & $0,3 \pm 0,1$ & $47,4 \pm 22,6$ & $23,2 \pm 1,2$ & $10,0 \pm 3,7$ \\
Klinefelter-Syndrom (5) & 0 & $25,4 \pm 7,5$ & $13,6 \pm 8,5$ & $34,3 \pm 5,3$ & $7,5 \pm 7,5$ \\
obstruktive Azoospermie (4) & 0 & $2,7 \pm 0,1$ & $199,0 \pm 26,3$ & $32,0 \pm 2,4$ & $17,8 \pm 1,8$ \\
nicht-obstruktive Azoospermie (29) & 0 & $23,4 \pm 2,9$ & $20,5 \pm 6,43$ & $28,8 \pm 1,1$ & $7,8 \pm 1,8$ \\
\hline
\end{tabular}




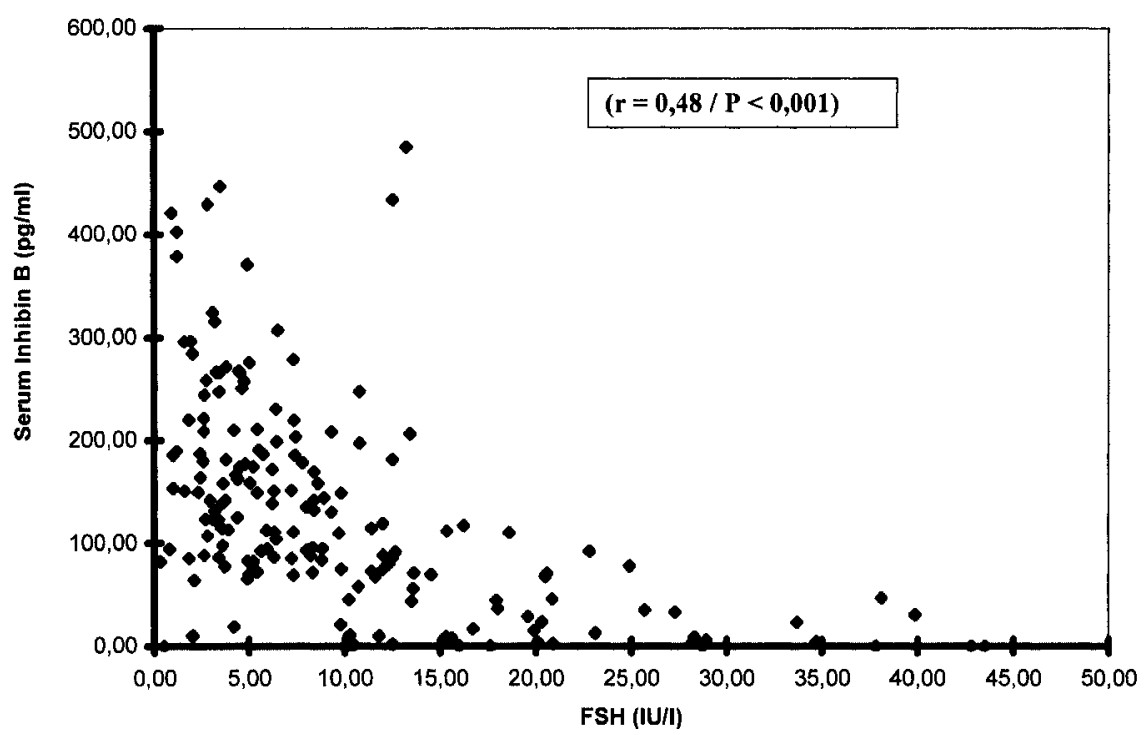

Abb. 1 Serum-Inhibin-B- und FSH-Korrelation bei allen Probanden.

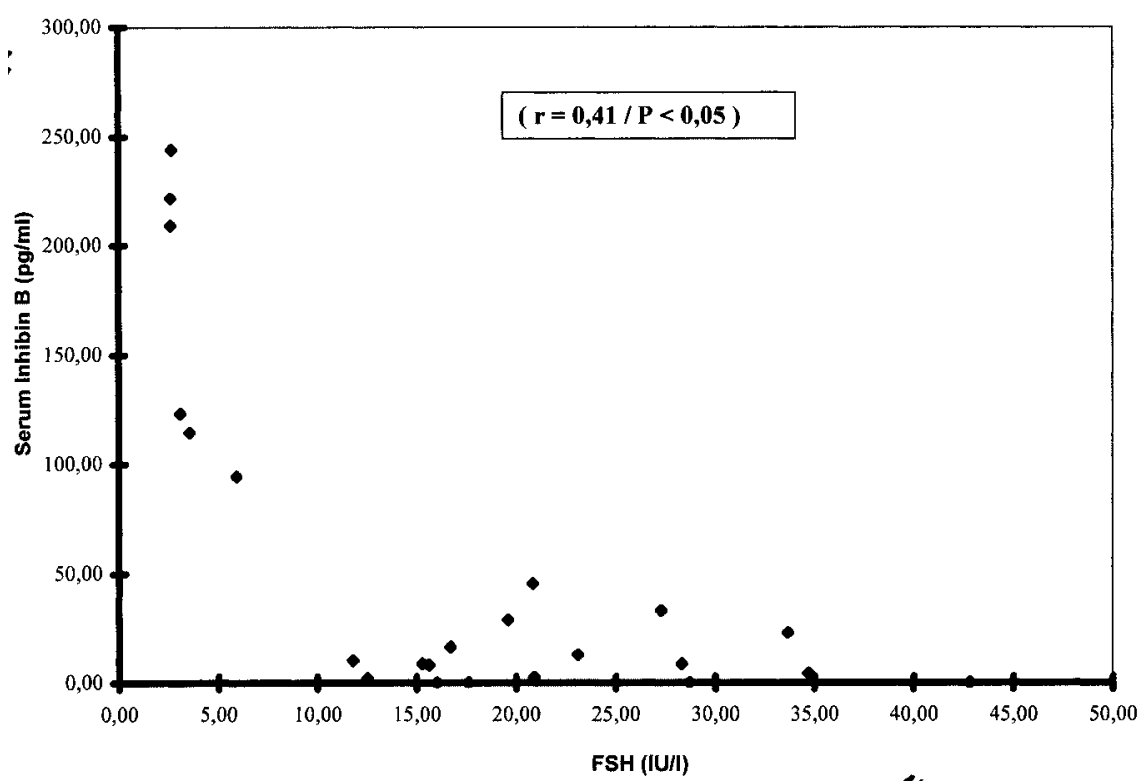

Abb. 2 Serum-Inhibin-B- und FSH-Korrelation bei der Patientengruppe mit nichtobstruktiver Azoospermie.

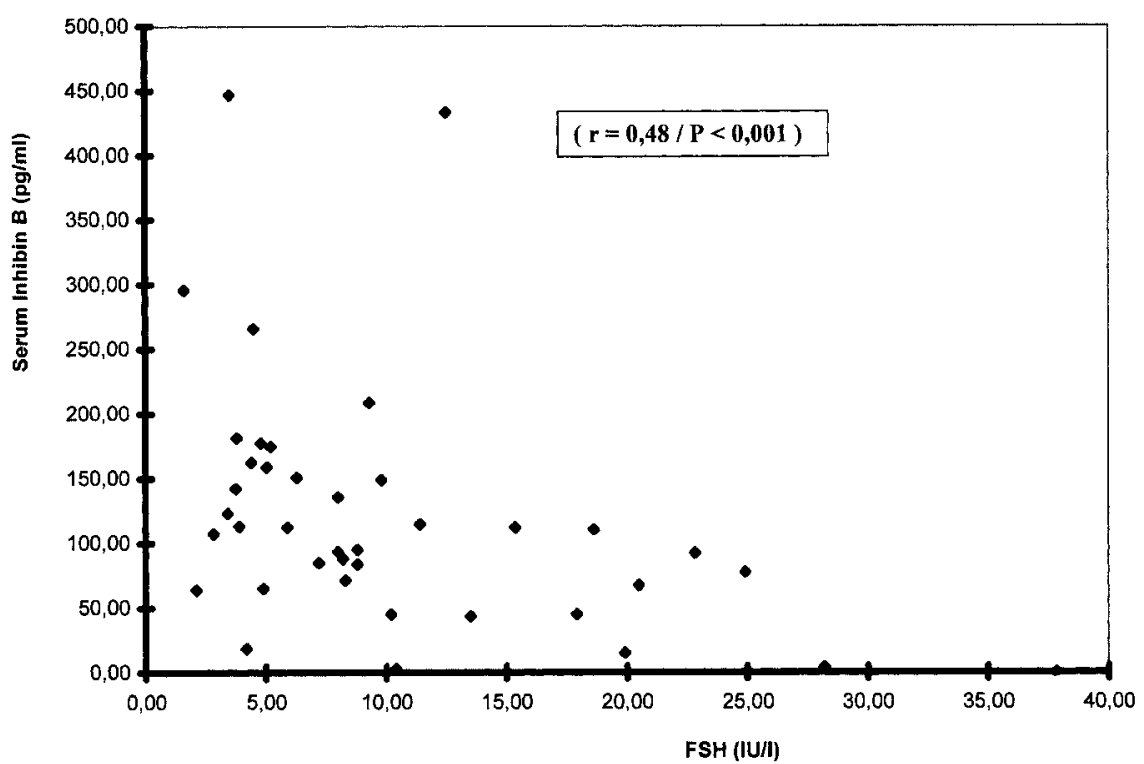

Abb. 3 Serum-Inhibin-B- und FSH-Korrelation bei der subfertilen Patientengruppe. 


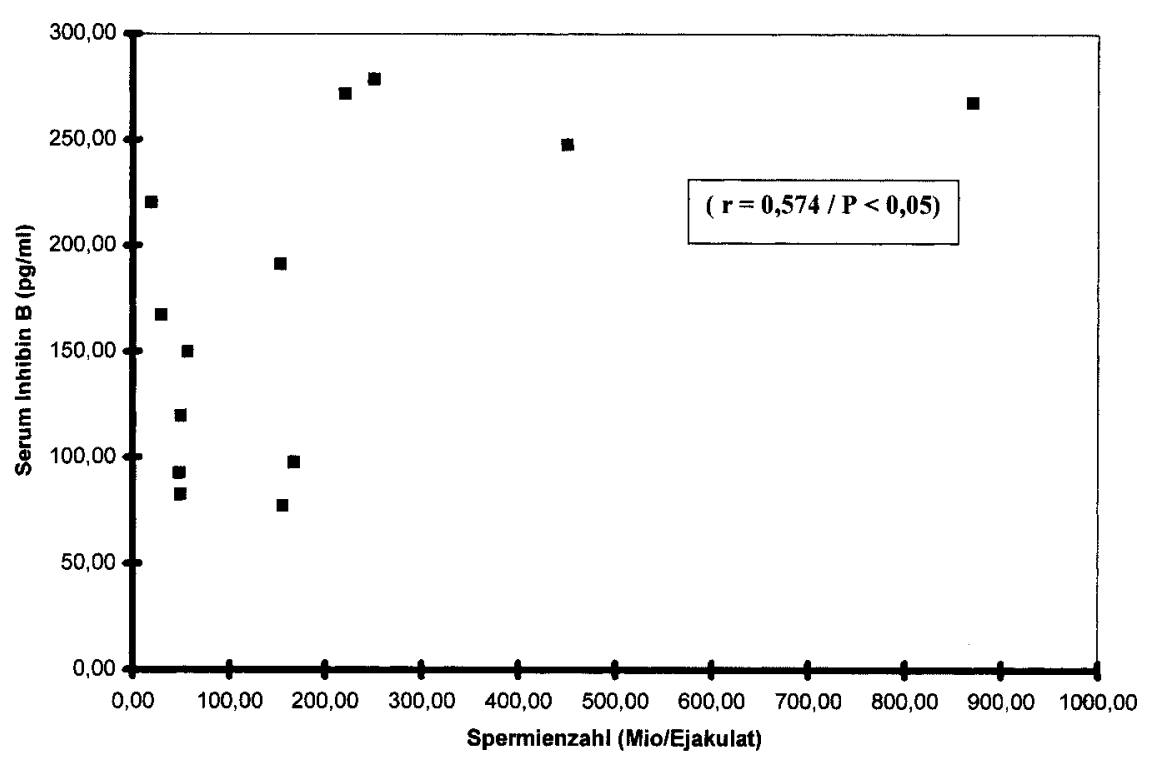

Abb. 4 Serum-Inhibin-B- und SpermienzahlKorrelation bei Patienten mit Varikozele.

$P=0,012)$ zu finden war. Sowohl bei präpubertären als auch bei pubertären Jungen wurde jedoch eine positive Korrelation zwischen Inhibin $B$ und Testosteron $(r=0,81, P=0,008$ und $r=0,62, P=0,054)$ beobachtet. Bei Jungen nimmt die testikuläre Produktion von Inhibin B als pubertärer Verlaufsparameter zu. Die Ergebnisse von Crofton et al. [5] machen erstmals deutlich, dass die Initiierung der Pubertät mit einem deutlichen Umschalten von einer positiven zu einer negativen Korrelation zwischen Inhibin B und FSH verbunden ist. Mit diesen Untersuchungen konnte auch gezeigt werden, dass der Inhibin-B-Assay ein nützliches Instrument für die Bestimmung der gonadalen Reifung in der späten präpubertären Phase und frühen Phase der Pubertät darstellt.

In unserer Studie konnte eine signifikante Korrelation zwischen Spermienkonzentration, Spermienzahl und testikulären Volumina auf der einen Seite und Serum-Inhibin B auf der anderen Seite gefunden werden. Diese Ergebnisse erbringen einen deutlichen Beweis, dass Inhibin B ein wichtiger Marker für die Kompetenz der Sertoli-Zellen und der Spermatogenese beim Mann ist. Dies steht in guter Übereinstimmung mit den Arbeiten von Klingmüller et al. [14], Illingworth et al. [10], Anawalt et al. [2] und Jensen et al. [11]. Besonders die Arbeit von Pierik et al. [17] liefert einen zusätzlichen Beweis für die Bedeutung des Inhibin B als Marker der Spermatogenese, wird doch hier eine statistisch signifikant positive Korrelation zwischen Inhibin B und der Beurteilung der Spermatogenese durch den testikulären Biopsiescore gefunden.

Pierik [17] untersuchte dabei bei Patienten mit kompetenter und gestörter Spermatogenese die Genauigkeit der Übereinstimmung der FSH- und Inhibin-B-Level mit dem JohnsonScore. Mit Hilfe der ROC-Kurve wurde Inhibin B als Marker mit der besten diagnostischen Aussage ermittelt. Eine multiple lineare Regressionsanalyse zeigte, dass FSH keine zusätzliche Bedeutung für den Johnson-Score über das Inhibin B hinaus hat. Die Auswahl der Cut-off-Werte für Inhibin B oder FSH ist dabei für die Unterscheidung zwischen kompetenter oder gestörter Spermatogenese maßgeblich.
Pierik et al. [17] wählten als Normalbereich für Inhibin B $140,6 \mathrm{pg} / \mathrm{ml}(140,6-225,7 \mathrm{pg} / \mathrm{ml})$ in einer Gruppe von 18 Samenspendern. Der von uns ermittelte Wert für Normalpersonen liegt bei $201 \pm 17,1 \mathrm{pg} / \mathrm{ml}$.

Die präsentierten Daten zeigen deutliche Unterschiede in den mittleren Inhibin-B-Konzentrationen bei den verschiedenen diagnostischen Untergruppen. Die Inhibin-B-Werte von Patienten mit einem spermatogenetischen Defekt waren signifikant niedriger im Vergleich zu einer Gruppe von Männern mit Normozoospermie. Patienten mit Obstruktionen als alleinige Ursache für eine Azoospermie hatten normale Inhibin-B-Werte. Dabei muss besonders hervorgehoben werden, dass offensichtlich nur die Auswahl des „richtigen“ Inhibin B-ELISA zu befriedigenden Ergebnissen führt. Es handelt sich dabei um den von Groome et al. [7] entwickelten Test. In Arbeiten, die unter Verwendung des Monash-RIA durchgeführt wurden, konnten keine vergleichbaren Ergebnisse erzielt werden. Der wichtigste Faktor für eine hohe Messwertgüte bei dem von Groome entwickelten Assay ist die Aufbereitung der Proben vor der eigentlichen ELISA-Ausführung und die Verwendung der eigens für diesen Test entwickelten Antikörper.

Ein weiterer Vorzug der Inhibin-B-Messungen ist, dass sie die Funktion des gesamten testikulären Gewebes reflektieren. Besonders von Pierik et al. [17] wird deshalb betont, dass man die Zahl der invasiven testikulären Biopsien deutlich reduzieren kann, wenn man die Inhibin-B-Werte hinsichtlich ihrer Aussage zur Funktionalität der Spermatogenese richtig deutet. FSH wurde bis jetzt als der wichtigste endokrine Marker für die testikuläre Funktion betrachtet [3]. Der diagnostische Wert von Inhibin B für die Beurteilung von spermatogenetischen Störungen scheint jedoch höher zu sein. Dies kann durch die Tatsache erklärt werden, dass Inhibin ein direktes Produkt der Tubuli seminiferi ist [13].

Im Gegensatz dazu werden die FSH-Level durch GnRH, Estradiol und Testosteron beeinflusst. Zusammenfassend lässt sich durch unsere Untersuchungen die Rolle von Inhibin B in der FSH-Regulation bestätigen. Wir fanden eine deutliche Korrelation von Serum-Inhibin-B-Werten und Hodenvolumina 
( $r=0,96, P<0,0005)$ und können somit bestätigen, dass Inhibin B der beste bekannte endokrine Marker für die Spermatogenese zu sein scheint.

\section{Literatur}

${ }^{1}$ Allenby G, Foster PM, Sharpe RM. Evaluation of changes in secretion of immunoactive inhibin by adult rat seminiferous tubules in vitro as an indicator of early toxicant action on spermatogenesis. Fundam Appl Toxicol 1991; 16: 710 - 724

${ }^{2}$ Anawalt BD, Bebb RA, Matsumoto AM. Serum inhibin B level reflects sertoli cell function in normal men and men with testicular dysfunction. J Clin Endocriol Metab 1996; 81: 3341 - 3345

${ }^{3}$ Bergmann M, Behre HM, Nieschlag E. Serum FSH and testicular morphology in male infertility. Clin Endocrinol 1994; 40: $133-$ 136

${ }^{4}$ Carroll RS, Kowash PM, Lofgren JA, Schwall RH, Chin WW. In vivo regulation of FSH synthesis by inhibin and activin. Endocrinology 1991; 129: 3299-3304

${ }^{5}$ Crofton PM, Illingworth PJ, Groome NP, Stirling HF, Swanston J, Gow S, Wu FCW, Mc Neilly A, Kelnar CJH. Changes in dimeric Inhibin A during normal early puberty in boys and girls. Clin Endocrinol 1997; 46: 109-114

${ }^{6}$ De Kretser DM, McFarlane JR. Inhibin in the male. J Androl 1996; 17: $179-182$

${ }^{7}$ Groome NP, O'Brien M. Immunoassays for inhibin and its subunits. Further applications of the synthetic peptide approach. J Immunol Method 1993; 165: 167-176

${ }^{8}$ Groome NP, O’Brien M. Preparation and applications of monoclonal antibodies to inhibin and its subunits. Frontiers in Endocrinol 1994; 3: $33-44$

${ }^{9}$ Hasegawa Y, Miyamoto K, Sugino H, Takio K, Inoue M, Ibuki Y. Progress with Human and Rat Inhibin Characterization. In: Burger HG, Findleay J, Robertson D, De Kretser DM, Petraglia F. Inhibin and Inhibin Related Proteins. Ares Serono Symposia Publications, 1994

10 Illingworth PJ, Groome NP, Bryd W. Inhibin-B: A likely candidate for the physiologically important form of inhibin in man. J Clin Endocrinol Metab 1996; 81: 1321 - 1325

${ }^{11}$ Jensen TK, Anderson AM, Hjollund NHI. Inhibin B as a serum marker of spermatogenese: correlation to differences in sperm concentration and follicle-stimulating hormone levels. A study of 349 Danish men. J Clin Endocrinol Metab 1997; 82: 40594063

12 Kitahara S, Kotsuji F, Keeping HS, Oshima H, Troen P, Winter SJ. Interrelationship between the actions of testosterone and primate sertoli cell inhibin in the control of gonadotropin secretion by cultured pituitary cells. Endocrinology 1991; 128: 710-716

${ }^{13}$ Klaij JA, van Pelt AM, Timmermann MA, Blok LJ, de Rooij DG, de Jong FH. Expression of inhibin subunit mRNA's and inhibin levels in the testes of rats with stage-synchronized spermatogenesis. J Endocrinol 1994; 141: 131 - 141

${ }^{14}$ Klingmüller D, Haidl G. Inhibin B in men with normal and disturbed spermatogenesis. Human Reproduction 1997; 12: $2376-2378$

${ }^{15}$ Knight PG, Muuttukrishna S. Measurement of dimeric inhibin using a modified two site immunoradiometric assay specific for oxidized (Met O) inhibin. J Endocrinol 1994; 141: 417-425

${ }^{16}$ McCullagh DR. Dual endocrine activity of testes. Science 1932; 76: $17-20$

${ }^{17}$ Pierik FH, Vreeburg JTM, Stijnen T, De Jong FH, Weber RFA. Serum Inhibin B as a Marker of Spermatogenesis. J Clin Endocrinol Metab 1998; 83: $3110-3114$

${ }^{18}$ Robert J, Wolley MD. Contraception - A Look Forward. Part III: Inhibin and Brain - Enhanced Estrogen Delivery. J Am Board Fam Pract 1991; 4: 159-166
${ }^{19}$ Robertson D, Burger HG, Sullivan J. Biochemical and immunological characterization of inhibin forms in human plasma. J Clin Endocrinol Metab 1996; 81: 669-676

${ }^{20}$ Robertson DM, Sullivan J, Watson M, Cahir N. Inhibin forms in human plasma. J Endocrinol 1955; 144: 261 - 269

${ }^{21}$ Simpon BJ, Hedger MP, DeKretser DM. Characterization of adult Sertoli cell cultures from cryptorchid rats: inhibin secretion in response to follicle-stimulating hormone stimulation. Mol Cell Endocrinol 1992; 87: 167-177

${ }^{22}$ WHO-Laborhandbuch zur Untersuchung des menschlichen Ejakulates und der Spermien-Zervikalschleim-Interaktion, 3. Auflage. Springer, 1993

\section{Dr. Uta-Christina Hipler}

Klinik für Dermatologie

Friedrich-Schiller-Universität

Erfurter Straße 35

07740 Jena

E-mail: chip@derma.uni-jena.de 